\title{
Disease-free and overall survival after neoadjuvant chemotherapy in breast cancer: breast-conserving surgery compared to mastectomy in a large single-centre cohort study
}

\author{
Janine M. Simons ${ }^{1}$ D . Julien G. Jacobs ${ }^{1} \cdot$ Joost P. Roijers $^{1} \cdot$ Maarten A. Beek $^{1} \cdot$ Leandra J. M. Boonman-de Winter $^{2}$. \\ Arjen M. Rijken ${ }^{1}$ - Paul D. Gobardhan ${ }^{1}$ - Jan H. Wijsman ${ }^{1}$ • Eric Tetteroo ${ }^{3}$ • Joan B. Heijns ${ }^{4} \cdot$ C. Y. Yick ${ }^{5}$. \\ Ernest J. T. Luiten ${ }^{1}$
}

Received: 28 July 2020 / Accepted: 5 October 2020 / Published online: 19 October 2020

(c) The Author(s) 2020

\begin{abstract}
Purpose The extended role of breast-conserving surgery (BCS) in the neoadjuvant setting may raise concerns on the oncologic safety of BCS compared to mastectomy. This study compared long-term outcomes after neoadjuvant chemotherapy (NAC) between patients treated with BCS and mastectomy.

Methods All breast cancer patients treated with NAC from 2008 until 2017 at the Amphia Hospital (the Netherlands) were included. Disease-free and overall survival were compared between BCS and mastectomy with survival functions. Multivariable Cox proportional hazard regression was performed to determine prognostic variables for disease-free survival.

Results 561 of 612 patients treated with NAC were eligible: 362 (64.5\%) with BCS and 199 (35.5\%) with mastectomy. Median follow-up was 6.8 years (0.9-11.9). Mastectomy patients had larger tumours and more frequently node-positive or lobular cancer. Unadjusted five-year disease-free survival was $90.9 \%$ for BCS versus $82.9 \%$ for mastectomy $(p=.004)$. Unadjusted five-year overall survival was $95.3 \%$ and $85.9 \%(p<.001)$, respectively. In multivariable analysis, clinical T4 (cT4) (HR 3.336, 95\% CI 1.214-9.165, $p=.019$ ) and triple negative disease (HR 5.946, 95\% CI 2.703-13.081, $p<.001$ ) were negative predictors and pathologic complete response of the breast (HR 0.467, 95\% CI 0.238-0.918, $p=.027$ ) and axilla (HR 0.332, 95\% CI 0.193-0.572, $p=.001)$ were positive predictors for disease-free survival. Mastectomy versus BCS was not a significant predictor for disease-free survival when adjusted for the former variables (unadjusted HR 2.13 (95\%CI: 1.4-3.24), adjusted HR 1.31 (95\%CI: 0.81-2.13)). In the BCS group, disease-free and overall survival did not differ significantly between cT1, cT2 or cT3 tumours.
\end{abstract}

Conclusion BCS does not impair disease-free and overall survival in patients treated with NAC. Tumour biology and treatment response are significant prognostic indicators.

Keywords Breast cancer $\cdot$ Lumpectomy $\cdot$ Mastectomy $\cdot$ Survival $\cdot$ Neoadjuvant chemotherapy $\cdot$ Breast-conserving surgery

Janine M. Simons

j.simons@erasmusmc.nl

1 Department of Surgical Oncology, Amphia Hospital, Postbus 90158, 4800 RK Breda, The Netherlands

2 Research Department, Amphia Hospital, Breda, The Netherlands

3 Department of Radiology, Amphia Hospital, Breda, The Netherlands

4 Department of Medical Oncology, Amphia Hospital, Breda, The Netherlands

5 Department of Pathology, Amphia Hospital, Breda, The Netherlands

\section{Introduction}

Over the past 20 years, neoadjuvant chemotherapy (preoperative chemotherapy; NAC) is increasingly used in earlystage breast cancer. Besides in vivo monitoring of treatment response, the tumour load in the breast can be reduced as a result of NAC. This enables surgeons to proceed more often to breast-conserving surgery (BCS) in patients initially scheduled for mastectomy [1]. The rate of BCS in patients treated with NAC has increased further with advances in imaging techniques to assess treatment response and techniques to localise breast lesions [2,3]. The use of iodine seeds facilitated the excision of multifocal lesions [3]. 
In patients treated with adjuvant chemotherapy, BCS has been shown to be a safe alternative to mastectomy in terms of survival [4-6]. More contemporary cohorts even reported improved survival rates for patients treated with BCS compared to mastectomy [7-10]. In a large population-based study of over 69,000 patients treated from 2006 until 2012, BCS was associated with superior breast cancerspecific and overall survival for T1-2N0-1 breast cancer [9]. Regarding the neoadjuvant setting, however, a meta-analysis by the Early Breast Cancer Trialists' Collaborative Group (EBCTCG) on long-term outcomes of neoadjuvant versus adjuvant chemotherapy reported higher local recurrence rates for BCS [11]. Breast cancer-specific mortality, on the other hand, was not increased [11]. This meta-analysis has several limitations: patients were treated up until 2005, the effect of radiotherapy was not studied and some patients did not undergo any surgery in case of complete clinical/ radiological response to NAC [12].

The aim of this study was to provide further insight into the long-term outcomes of BCS in patients treated with NAC. Local, regional and distant recurrence rates together with overall survival data of BCS were compared to mastectomy in breast cancer patients treated with NAC at a large teaching hospital in the Netherlands.

\section{Methods}

Female breast cancer patients treated with NAC between April 2008 and March 2017 at the Amphia Hospital (Breda, The Netherlands) were identified from the Netherlands Cancer Registry (NCR). In the NCR, data are collected from all patients with cancer in the Netherlands and it is managed by 'Integraal Kankercentrum Nederland' (IKNL). Data on vital status or emigration were derived from the Municipal Personal Records Database (Basisregistratie Personen, BRP).

Patients were excluded in case of distant disease at diagnosis, history of breast cancer, treatment termination after one or two cycles of chemotherapy, when surgery of the breast was not performed or when patients were lost to follow-up (i.e. follow-up visits after surgery did not take place).

Data on patient, tumour and treatment characteristics were collected retrospectively. The reported clinical tumour and node status represent the pre-NAC clinical status. Regarding the post-NAC tumour and node status, it was reported whether or not a pathologic complete response (pCR) was achieved. In addition, medical records were reviewed to retrieve data on follow-up and recurrences to complement the NCR data. The Institutional Board of Directors approved the study protocol (N2018-0137).

Standard work-up included mammography, axillary ultrasound and magnetic resonance imaging (MRI). Fine needle aspiration or core needle biopsy was performed in case of suspicious axillary lymph nodes. In all patients treated with NAC, response monitoring was performed by breast MRI. Multifocal or multicentric disease was diagnosed on imaging studies and/or pathologic analysis. Staging imaging studies for distant metastasis were performed before the start of NAC. Initially, this was performed by a combination of chest radiograph, ultrasound of the liver and the periclavicular lymph nodes and bone scintigraphy, and this was gradually replaced by positron emission tomography-computed tomography scan (PET-CT) during the study period.

NAC regimens were determined based on the applicable Dutch breast cancer guideline [13] and based on recommendations from the multidisciplinary tumour board. HER2-positive patients received HER2-targeted therapy in addition to chemotherapy. Local surgery consisted of either BCS or mastectomy. In case of more than focally positive margins after BCS, re-excision (i.e. repeat BCS or mastectomy) was indicated. Regional surgery consisted of sentinel lymph node biopsy (SLNB) for clinically node-negative patients or axillary lymph node dissection for clinically node-positive patients or patients with a positive SLNB. SLNB was generally performed prior to NAC, which was standard SLNB timing during the time frame of this study. Only during the last year of the study period, timing of SLNB changed from pre-NAC to post-NAC. Indications for adjuvant radiotherapy were also based on the Dutch breast cancer guidelines and recommendations from the multidisciplinary tumour board. Over the course of the study period, guidelines for regional adjuvant therapy changed, which resulted in extended indications for omission of ALND or replacement of ALND by radiotherapy.

The definition of axillary pCR (ypN0) included isolated tumour cells. A positive SLNB prior to NAC (isolated tumour cells and/or micrometastasis) was included in the definition of axillary pCR as well (unless ALND was performed after NAC and micro- or macrometastasis were identified).

The primary endpoint measures were recurrence and disease-free survival. Recurrence was regarded as any local, regional or distant tumour recurrence. Disease-free survival was defined as the time interval between date of diagnosis and date of first recurrence or last follow-up or death, whichever came first. The secondary outcome measure was overall survival, defined as the time interval between date of diagnosis and date of last follow-up or death (related to breast cancer or death of any cause). Patients alive at last follow-up or lost to follow-up were censored. Events occurring within 91 days were considered synchronous with the primary breast cancer. Data on follow-up were collected until February 28, 2020. 


\section{Statistical analysis}

Independent samples $t$ tests and chi-square tests were used to compare clinical and tumour characteristics between patients treated with BCS or mastectomy.

Survival rates were examined for all included patients with Kaplan-Meier curves and compared between BCS and mastectomy with the log-rank test. For both disease-free and overall survival, survival rates were calculated for a specified survival period of five years. Relevant clinicopathologic characteristics were examined using univariable analysis for their association with disease-free survival. Variables with a $p$ value $\leq 0.2$ were candidates for multivariable Cox proportional hazard regression analysis. Results were reported with hazard ratios (HR) for recurrent disease and corresponding 95\% confidence intervals.

Statistical analyses were performed with the Statistical Package for the Social Sciences software (Version 26, IBM, Armonk, New York, USA).

\section{Results}

From April 2008 until March 2017, a total of 612 nonmetastatic breast cancer patients were treated with NAC at the Amphia Hospital in Breda, the Netherlands. From this cohort, a total of 561 patients were eligible for analysis as they were treated for primary invasive breast cancer, completed at least three cycles of NAC, underwent surgery and had data on follow-up (see Fig. 1 for the CONSORT diagram and Table 1 for patient and tumour characteristics). BCS was performed in 362 (64.5\%) patients and mastectomy in 199 (35.5\%) patients. In two patients treated with BCS, adjuvant radiotherapy was omitted at the patient's request. The rate of BCS increased from $20 \%$ in 2008 to $77.8 \%$ in 2017.

Mastectomy patients more often had higher clinical tumour status, node-positive disease, lobular cancer and multifocal/multicentric disease compared to BCS patients prior to NAC. Two patients had positive margins after mastectomy $(1 \%)$ and were treated with additional locoregional radiotherapy. In the BCS group, free margins were achieved in all patients. The overall breast pCR rate was $23.4 \%$ : $25.7 \%$ in the BCS group and $19.1 \%$ in the mastectomy group $(p=0.077)$. In 439 patients with ductal breast cancer, 108 (24.6\%) patients achieved a pCR of the breast. In 65 patients with lobular cancer, only 3 (4.6\%) patients achieved a pCR of the breast. Of all 131 patients with a breast pCR, 93 (71\%) patients underwent BCS.

Regarding regional surgery, SLNB was performed in 280/302 (92.7\%) cN0 patients: in 97.5\%, SLNB was performed prior to NAC, and in the remainder, SLNB was performed post-NAC. In 86/280 (30.7\%), cN0 patients, axillary lymph node dissection was performed following a positive
SLNB. In 22/302 (7.3\%) cN0 patients, SLNB was deemed contraindicated and ALND was performed (e.g. in case of clinically/radiologically suspicious lymph nodes despite negative cytology). In 256/259 (98.8\%) cN + patients, ALND was performed (two $\mathrm{cN}+$ patients underwent SLNB post-NAC and one $\mathrm{cN}+$ patient opted for axillary radiotherapy instead of ALND). Overall, ALND was performed in 364 (64.9\%) patients $(55.2 \%$ in BCS patients and $81.9 \%$ in mastectomy patients).

\section{Disease-free and overall survival}

Median follow-up for disease-free survival was 5.7 years (0.5-11.2). In total, 87 (15.5\%) patients experienced a recurrence event: 41/362 (11.3\%) in the BCS group and 46/199 (23\%) in the mastectomy group (see Table 2). Unadjusted five-year disease-free survival was $88.1 \%$ overall: $90.9 \%$ following BCS and $82.9 \%$ following mastectomy $(p=0.004$, see Fig. 2 for survival functions).

Median follow-up for overall survival was 6.8 years (0.9-11.9). At the time of analysis, 65 (11.6\%) patients had died: in 51 (78.4\%) patients, death was related to breast cancer, in $10(15.4 \%)$ patients death was not related to breast cancer and in 4 (6.2\%) patients cause of death was unknown.

Unadjusted five-year overall survival was $92 \%$ : $95.3 \%$ following BCS and $85.9 \%$ following mastectomy $(p<0.001$, see Fig. 3 for survival functions).

\section{Predictors of recurrence}

In univariable analysis (see Table 3), grade, multifocal/multicentric disease and age were non-significant variables for disease-free survival. Grade had a $p$ value $<0.2$, but was not included in the multivariable analysis due to the high amount of missing data for this variable. Clinical tumor status (pre-NAC), clinical node status (pre-NAC), subtype, type of breast surgery and response in the breast and axilla were all significant variables and were included in the multivariable analysis. Multivariable Cox regression analysis showed that clinical T4 tumours (HR 3.336, 95\% CI 1.214-9.165, $p=0.019$ ) and triple negative disease (HR 5.946, 95\% CI 2.703-13.081, $p<0.001)$ were significantly associated with decreased disease-free survival. A pCR of the breast (HR $0.467,95 \%$ CI $0.238-0.918, p=0.027$ ) and also of the axilla (HR $0.332,95 \%$ CI $0.193-0.572, p<0.001$ ) were significantly associated with improved disease-free survival. Multivariable Cox regression analysis did not demonstrate a significant difference between treatment with BCS or mastectomy (see Table 4). Mastectomy had an unadjusted HR for recurrent disease of 2.13 (95\% CI 1.4-3.24) and when adjusted for pre-NAC clinical tumour and node status, subtype, breast pCR and axillary pCR, mastectomy had a HR 
Fig. 1 Consort flow diagram for included patients

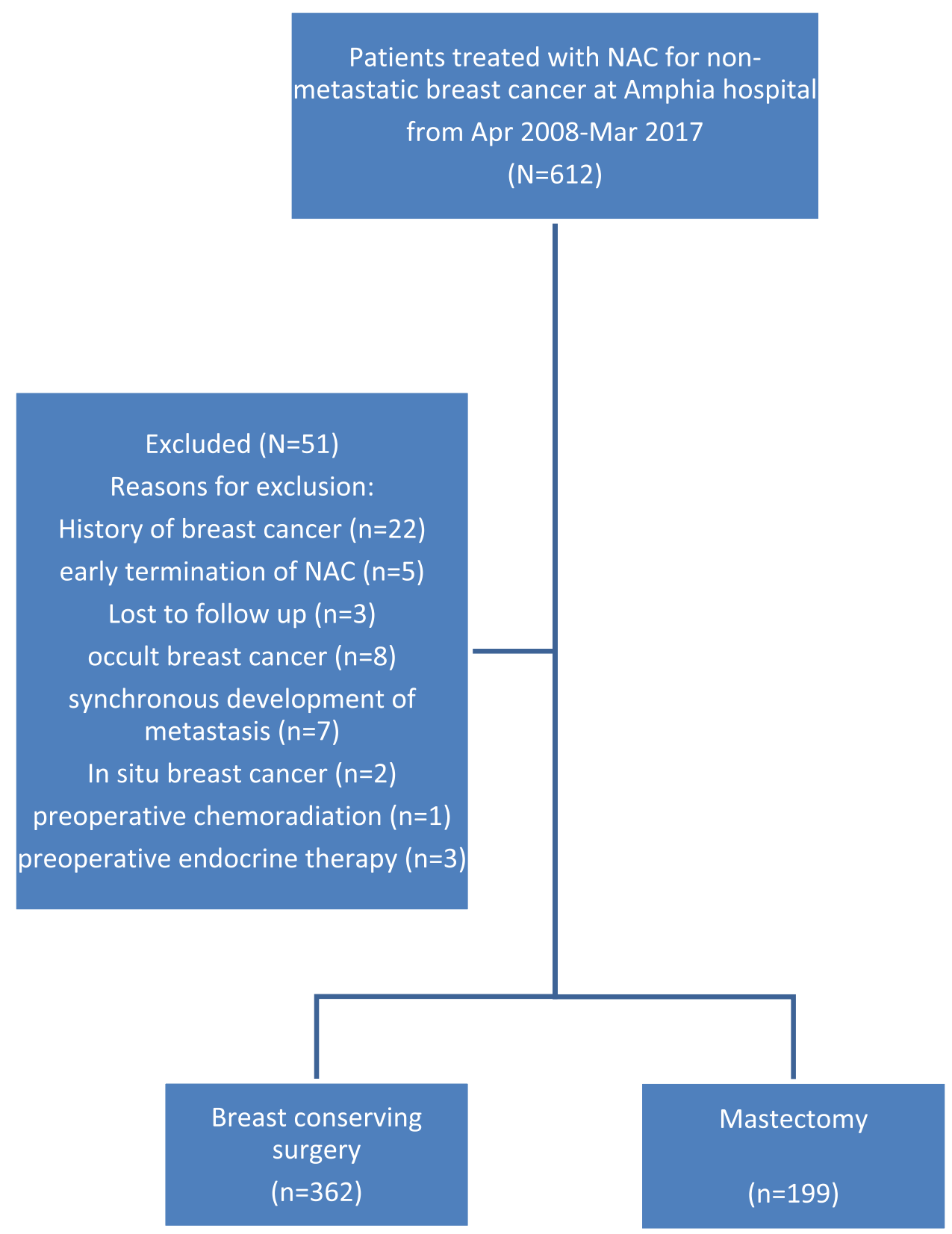

of 1.31 (95\%CI 0.81-2.13). Adjusted survival functions are provided in Fig. 4.

\section{Breast-conserving surgery in pre-NAC clinical T3 disease}

A total of $356 / 362$ patients underwent BCS for clinical T1-T3 tumors. Five-year disease-free survival was $88.9 \%$, $91.5 \%$ and $88.5 \%$ for cT 1 , cT2, and cT3 tumours, respectively $(p=0.656)$. Five-year overall survival was $96.3 \%$, $94.8 \%$ and $96.2 \%$, respectively $(p=0.844)$.

In 199 patients that underwent mastectomy, 179 patients had clinical T1-T3 tumours. Higher clinical tumour status was associated with decreased survival, but this finding was not statistically significant. Five-year disease-free survival was $93.3 \%, 87.3 \%$ and $83.5 \%(p=0.462)$, respectively. Five-year overall survival was $93.3 \%, 88.6 \%$ and $88.6 \%$ $(p=0.826)$, respectively.

\section{Discussion}

In this large, contemporary, single-centre cohort study of breast cancer patients treated with NAC, disease-free and overall survival were compared between BCS and mastectomy. In this cohort, the rate of BCS increased 
Table 1 Patient and tumour characteristics

\begin{tabular}{|c|c|c|c|c|}
\hline & $\begin{array}{l}\text { All patients } \\
N=561\end{array}$ & $\begin{array}{l}\text { BCS } \\
N=362(64.5 \%)\end{array}$ & $\begin{array}{l}\text { Mastectomy } \\
N=199(35.5 \%)\end{array}$ & $p$ value \\
\hline Age mean (range) & $50.42(23-81)$ & $50.65(24-81)$ & $49.99(23-74)$ & .481 \\
\hline Clinical tumour status (pre-NAC) & & & & $<.001$ \\
\hline $\mathrm{T} 1$ & $70(12.5)$ & $54(14.9)$ & $16(8.0)$ & \\
\hline $\mathrm{T} 2$ & $330(58.8)$ & $249(68.8)$ & $81(40.7)$ & \\
\hline $\mathrm{T} 3$ & $135(24.1)$ & $53(14.6)$ & $82(41.2)$ & \\
\hline $\mathrm{T} 4$ & $26(4.6)$ & $6(1.7)$ & $20(10.1)$ & \\
\hline Clinical node status (pre-NAC) & & & & $<.001$ \\
\hline Negative & $302(53.8)$ & $219(60.5)$ & $83(41.7)$ & \\
\hline Positive & $259(46.2)$ & $143(39.5)$ & $116(58.3)$ & \\
\hline \multicolumn{5}{|l|}{ Histology } \\
\hline Ductal & $439(78.3)$ & $298(82.3)$ & $141(70.9)$ & $<.001$ \\
\hline Lobular & $65(11.6)$ & $26(7.2)$ & $39(19.6)$ & \\
\hline Other & $57(10.2)$ & $38(10.5)$ & $19(9.5)$ & \\
\hline Subtype & & & & .589 \\
\hline HRposHER2neg & $323(57.6)$ & $208(57.5)$ & $115(57.8)$ & \\
\hline HRposHER2pos & $102(18.2)$ & $61(16.9)$ & $41(20.6)$ & \\
\hline HRnegHER2pos & $46(8.2)$ & $32(8.8)$ & $14(7.0)$ & \\
\hline Triple negative & $90(16.0)$ & $61(16.9)$ & $29(14.6)$ & \\
\hline Grade & & & & .635 \\
\hline I & $118(21.0)$ & $74(20.4)$ & $44(22.1)$ & \\
\hline II & $192(34.2)$ & $125(34.5)$ & $67(33.7)$ & \\
\hline III & $157(28.0)$ & $107(29.6)$ & $50(25.1)$ & \\
\hline Unknown & $94(16.8)$ & $56(15.5)$ & $38(19.1)$ & \\
\hline Multifocal or multicentric & & & & $<.001$ \\
\hline No & $389(69.3)$ & $297(82.0)$ & $92(46.2)$ & \\
\hline Yes & $172(30.7)$ & $65(18.0)$ & $107(53.8)$ & \\
\hline Breast pCR (ypT0) & & & & .077 \\
\hline No & $430(76.6)$ & $269(74.3)$ & $161(80.9)$ & \\
\hline Yes & $131(23.4)$ & $93(25.7)$ & $38(19.1)$ & \\
\hline Axillary pCR (ypN0) & & & & $<.001$ \\
\hline No & $170(30.3)$ & $77(21.3)$ & $93(46.7)$ & \\
\hline Yes & $385(68.6)$ & $282(77.9)$ & $103(51.8)$ & \\
\hline Unknown $^{\mathrm{a}}$ & $6(1.1)$ & $3(0.8)$ & $3(1.5)$ & \\
\hline Endocrine therapy & & & & .273 \\
\hline No & $145(25.8)$ & $99(27.3)$ & $46(23.1)$ & \\
\hline Yes & $416(74.2)$ & $263(72.2)$ & $153(76.9)$ & \\
\hline Targeted therapy & & & & .407 \\
\hline No & $412(73.4)$ & $270(74.6)$ & $142(71.4)$ & \\
\hline Yes & $149^{\mathrm{b}}(26.6)$ & $92(25.4)$ & $57(28.6)$ & \\
\hline
\end{tabular}

Values are numbers (\%) unless stated otherwise

HRposHER2neg hormone receptor-positive and HER2-negative breast cacer, HRposHER2pos hormone receptor-positive and HER2-positive breast cancer, HRnegHER2pos hormone receptor-negative and HER2positive breast cancer

a $5 \mathrm{cN} 0$ patients with pre-NAC SLNB positive for macrometastasis, without post-NAC axillary surgery and one $\mathrm{cN}+$ patient without ALND (ALND was replaced by regional radiotherapy at these patient's request)

${ }^{\mathrm{b}}$ One patient was inaccurately identified as HER2-positive prior to NAC and received HER2-targeted therapy 
Table 2 Recurrences by type of breast surgery

\begin{tabular}{llll}
\hline & Total (\%) & BCS (\%) & Mastectomy $(\%)$ \\
$N=561$ & $N=362(\%)$ & $N=199(\%)$ \\
\hline Any recurrence & $87(15.5)$ & $41(11.3)$ & $46(23.1)$ \\
Local recurrence & $18(3.2)$ & $10(2.8)$ & $8(4)$ \\
Regional recurrence & $18(3.2)$ & $8(2.2)$ & $10(5)$ \\
Distant recurrence & $72(12.9)$ & $33(9.2)$ & $39(19.7)$ \\
\hline
\end{tabular}

Values are numbers (\%) unless stated otherwise

substantially over the past decade. Despite the extended role of BCS in the neoadjuvant setting, BCS did not significantly affect disease-free survival in multivariable analysis. This supports the concept that BCS can be a safe option in the treatment of breast cancer following NAC.

The use of chemotherapy in the neoadjuvant setting increased substantially over the past decade, which facilitated translational research [14]. Despite inconsistent results of neoadjuvant trials, pathologic response is suggested to serve as a surrogate marker for risk of relapse and breast cancer survival. The neoadjuvant setting provides the possibility to tailor therapy in individual patients. Moreover, the possibility to test new regimens in much smaller trials and to obtain results far more rapidly than studies in the adjuvant setting [15] is probably one of the greatest advantages of the neoadjuvant setting.

Another spectacular result of the use of NAC is the increasing possibility to shift surgical treatment from preplanned mastectomy towards BCS, notably in case of pCR. Especially in large or multifocal tumours, there may be concerns on the oncologic safety of BCS. Despite this, BCS rates have increased with increased NAC use $[1,11,14$, 16-18]. In the present study, BCS rates increased over time up to almost $80 \%$ and approximately one-fifth of patients treated with BCS had multifocal/multicentric disease. A systematic review by Mieog et al., reported that there was no significant increased risk of locoregional recurrences associated with downstaged BCS [1]. In a cohort study of 2983 BCS patients, timing of chemotherapy did not impact locoregional recurrence free survival when patients were evaluated by presenting clinical stage [19]. In an EBCTCG meta-analysis published in 2018, including 10 randomised trials with a median follow-up of 9 years, local recurrences were more often observed in patients treated with BCS for downsized tumours by NAC than in patients treated with BCS in the adjuvant setting for tumours of the same dimensions [11]. Distant recurrences and breast cancer-specific or overall survival were not affected, however. Reduction of tumour load by NAC poses a challenge to surgeons to locate and subsequently radically excise the primary tumour site.
Fig. 2 Unadjusted survival functions for disease-free survival by type of breast surgery (including numbers at risk)

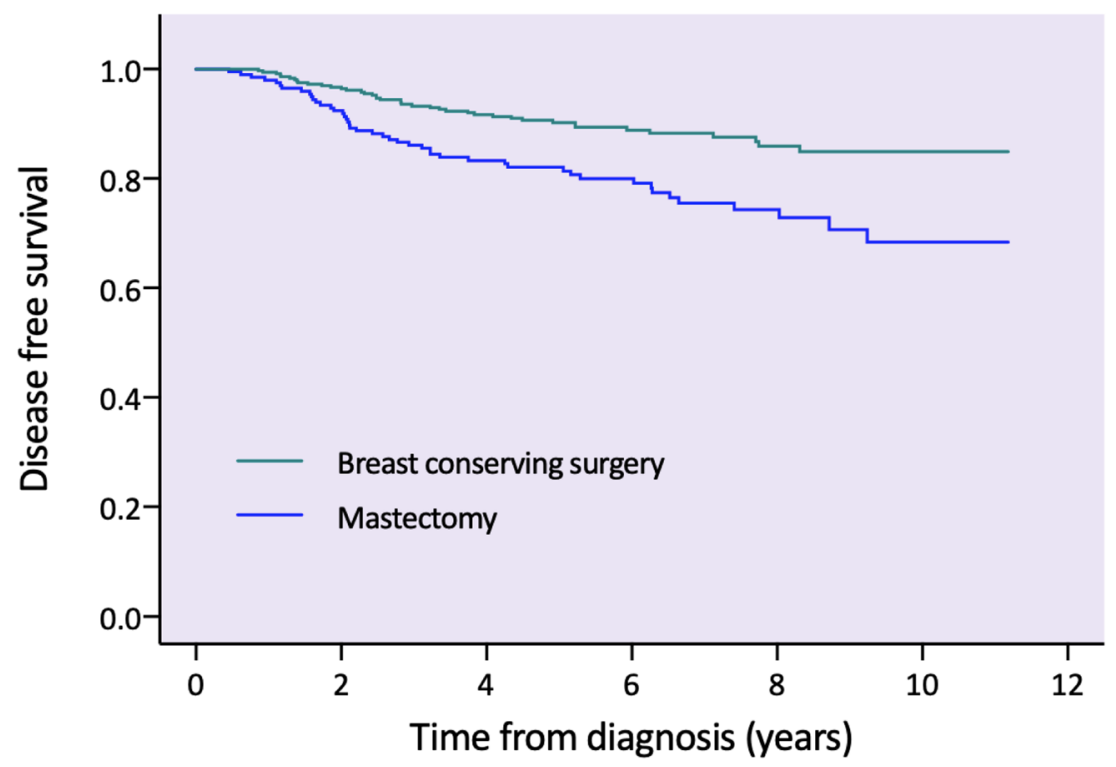

Numbers at risk

\begin{tabular}{|l|l|l|l|l|l|l|l|l|l|l|l|l|}
\hline $\begin{array}{l}\text { Interval } \\
\text { (years) }\end{array}$ & 0 & 1 & 2 & 3 & 4 & 5 & 6 & 7 & 8 & 9 & 10 & 11 \\
\hline BCS & 362 & 359 & 338 & 296 & 246 & 193 & 148 & 114 & 72 & 33 & 10 & 1 \\
\hline Mastectomy & 199 & 192 & 176 & 153 & 131 & 110 & 85 & 60 & 42 & 24 & 9 & 1 \\
\hline
\end{tabular}


Fig. 3 Unadjusted survival functions for overall survival by type of breast surgery (including numbers at risk)

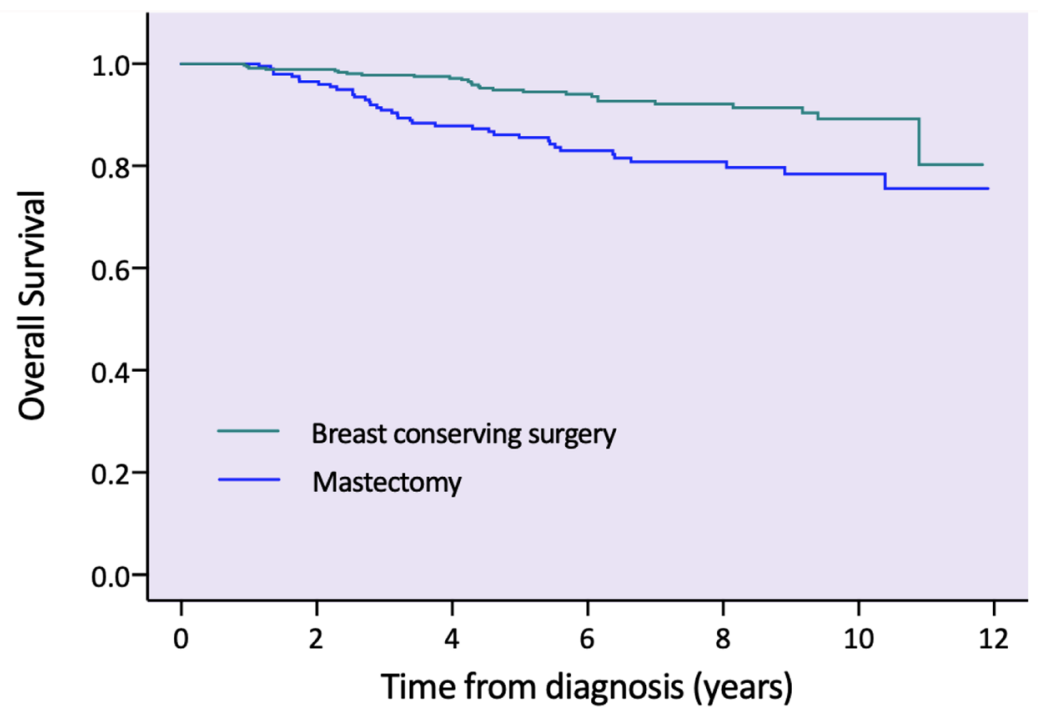

Numbers at risk

\begin{tabular}{|l|l|l|l|l|l|l|l|l|l|l|l|l|}
\hline $\begin{array}{l}\text { Interval } \\
\text { (years) }\end{array}$ & 0 & 1 & 2 & 3 & 4 & 5 & 6 & 7 & 8 & 9 & 10 & 11 \\
\hline BCS & 362 & 360 & 358 & 333 & 288 & 235 & 188 & 149 & 115 & 75 & 30 & 2 \\
\hline Mastectomy & 199 & 199 & 192 & 174 & 153 & 133 & 111 & 89 & 70 & 49 & 26 & 6 \\
\hline
\end{tabular}

Increased use of MRI, markers for better localisation of the lesion (like iodine seeds), thorough pathological assessment and radiotherapy are important strategies to decrease the chance of local recurrence. These factors were not accounted for in the review [12] but all are part of standard care nowadays. Apart from this, some included trials did not require surgery of the breast after NAC in case of complete clinical/ radiological response to treatment, to which the higher rate of local recurrences can be attributed.

In the current study, disease-free and overall survival were favourable for BCS patients compared to mastectomy patients. This difference did not hold after correcting for confounders. A few other 'neoadjuvant' cohort studies reported on the oncologic safety of BCS [20-24]. All reported that BCS did not affect survival compared to mastectomy. In the current study, clinical tumour size, subtype and treatment response were significant predictors for disease-free survival. This is in accordance with an analysis of predictors of recurrences after NAC in approximately 3000 patients that were included in the NASBP B-18 and B-27 trials [25]. While subtype was not analysed in that trial, other significant independent predictors were age and clinical node status. The effect different subtypes have on recurrence rates in patients treated with NAC has been demonstrated by several other studies [26-31], where the
HR-negative/HER2-positive and triple negative subtypes are associated with increased recurrence rates.

Data on the oncologic safety of BCS in cT3 tumours are not as extensive as that for patients with cT1-2 tumours, as cT3 tumours were often excluded from randomised controlled trials. Two large cohort studies (one only including patients $>65$ years) in which patients treated with NAC were also included, did not found a significant survival difference between BCS and mastectomy in cT3 disease $[32,33]$. In the BCS group of the current study, diseasefree and overall survival were not significantly different between cT1, cT2 or cT3 tumours. Hence, cT3 status prior to NAC should not merely preclude BCS.

A pCR of the breast was achieved in $23.4 \%$ of patients treated in the current cohort. This is consistent with other reports $[34,35]$. The multivariable analysis of this cohort showed that breast pCR as well as axillary pCR were significant predictors of improved survival. This is in agreement with findings from other studies, in which it is shown that patients with a pCR of both the breast and axilla have superior survival [36-38]. Since breast PCR is associated with improved prognosis, it is thought that some patients may not require any breast surgery at all. In a prospective trial of 40 patients with HER2-positive and triple negative breast cancer, image-guided sampling of the breast with a median of 12 biopsies appeared to accurately diagnose 
Table 3 Univariable analysis of relevant clinicopathologic characteristics for disease-free survival

\begin{tabular}{|c|c|c|c|}
\hline & $\begin{array}{l}\text { Disease-free survival } \\
\text { Yes } N=474(84.5)\end{array}$ & $\begin{array}{l}\text { Disease-free survival } \\
\text { No } N=87(15.5)\end{array}$ & $p$ value \\
\hline Age (mean, sd) & $50.34(10.20)$ & $50.82(12.09)$ & .733 \\
\hline Clinical tumour status (pre-NAC) & & & $<.001$ \\
\hline $\mathrm{T} 1$ & $70(88.6)$ & $8(11.4)$ & \\
\hline $\mathrm{T} 2$ & $330(87.3)$ & $42(12.7)$ & \\
\hline $\mathrm{T} 3$ & $135(80.0)$ & $27(20.0)$ & \\
\hline $\mathrm{T} 4$ & $26(61.5)$ & $10(38.5)$ & \\
\hline Clinical node status (pre-NAC) & & & $<.001$ \\
\hline Negative & $302(90.1)$ & $30(9.9)$ & \\
\hline Positive & $259(78.0)$ & $57(22.0)$ & \\
\hline Multifocal & & & .410 \\
\hline No & $389(85.6)$ & $56(14.4)$ & \\
\hline Yes & $172(82.0)$ & $31(18.0)$ & \\
\hline Subtype & & & .002 \\
\hline HRposHER2pos & $93(91.2)$ & $9(8.8)$ & \\
\hline HRposHER2neg & $273(84.5)$ & $50(15.5)$ & \\
\hline HRnegHER2pos & $41(89.1)$ & $5(10.9)$ & \\
\hline Triple negative & $67(74.4)$ & $23(25.6)$ & \\
\hline Grade & & & .071 \\
\hline I & $104(88.1)$ & $14(11.9)$ & \\
\hline II & $158(82.3)$ & $34(17.7)$ & \\
\hline III & $129(82.2)$ & $28(17.8)$ & \\
\hline Type of breast surgery & & & $<.001$ \\
\hline BCS & $321(88.7)$ & $41(11.3)$ & \\
\hline Mastectomy & 153 (76.9) & $46(23.1)$ & \\
\hline Breast pCR (ypT0) & & & .021 \\
\hline No & 355 (82.6) & $75(17.4)$ & \\
\hline Yes & $119(90.8)$ & $12(9.2)$ & \\
\hline Axillary pCR (ypN0) & & & $<.001$ \\
\hline No & $170(71.2)$ & $49(28.8)$ & \\
\hline Yes & $385(90.4)$ & 37 (9.6) & \\
\hline
\end{tabular}

Values are numbers (\%) unless stated otherwise

HRposHER2neg hormone receptor-positive and HER2-negative breast cancer, HRposHER2pos hormone receptor-positive and HER2-positive breast cancer, HRnegHER2pos hormone receptor-negative and HER2positive breast cancer, $p C R$ pathologic complete response
Table 4 Crude and adjusted Hazard Ratios (HR) for recurrent disease for mastectomy versus BCS

\begin{tabular}{lll}
\hline & $\begin{array}{l}\text { Crude HR (95\%CI) } \\
\text { Mastectomy vs BCS }\end{array}$ & $\begin{array}{l}\text { Adjusted }^{\mathrm{a}} \text { HR (95\%CI) } \\
\text { Mastectomy vs BCS }\end{array}$ \\
\hline Recurrent disease & $2.127(1.396-3.241)$ & $1.314(.812-2.127)$ \\
\hline
\end{tabular}

${ }^{a}$ Adjusted for clinical tumour status (pre-NAC), clinical node status (pre-NAC), subtype, breast pCR, and axillary pCR

pCR with a false negative rate of 5\% [39]. This has yet to be confirmed by large trials. Further research is needed to determine which minimally invasive method is most suitable to determine breast $\mathrm{pCR}$ and which subset of patients may safely forego any surgery of the breast.
The most important limitation of this study is the retrospective study design. The NCR data were complemented with reviewing medical records, which may have limited inconsistency inherent to retrospective data analysis. Patients primarily scheduled for mastectomy are more likely to have a poor prognosis to begin with. Also, with this study design, we could not account for all different reasons why a certain patient was treated with BCS and not mastectomy and vice versa. Furthermore, some patients were not treated according to current standards at their own request (such as replacement of ALND by regional radiotherapy or BCS not followed by local radiotherapy). Since this number is small it is unlikely that this significantly affected our results, and moreover, this cohort represents real-world experience. 


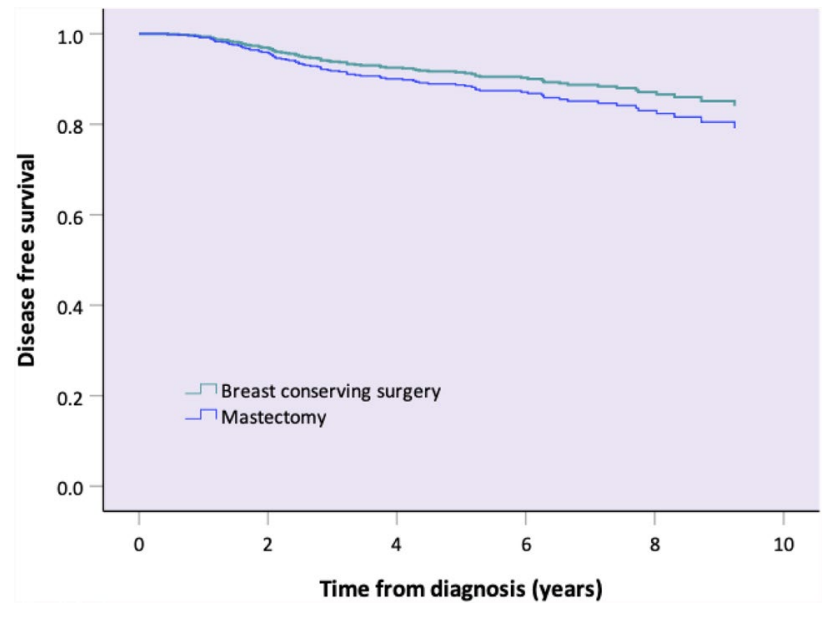

Fig. 4 Adjusted survival functions for disease-free survival by type of breast surgery

To conclude, BCS does not negatively affect survival in breast cancer patients treated with NAC and can be a safe treatment option, even in larger tumours. Tumour biology and treatment response appear to be important prognostic indicators. Further research is needed to advance patienttailored breast cancer treatment.

Funding This study was not funded.

\section{Compliance with ethical standards}

Conflict of interest All authors declare that they have no conflicts of interest.

Ethical approval All procedures performed in studies involving human participants were in accordance with the ethical standards of the institutional and/or national research committee and with the 1964 Helsinki declaration and its later amendments or comparable ethical standards.

Informed consent The requirement for informed consent was waived because of the retrospective nature of this study by the Medical Ethics Review Committee of the University Medical Center of Utrecht in the Netherlands (18/199).

Open Access This article is licensed under a Creative Commons Attribution 4.0 International License, which permits use, sharing, adaptation, distribution and reproduction in any medium or format, as long as you give appropriate credit to the original author(s) and the source, provide a link to the Creative Commons licence, and indicate if changes were made. The images or other third party material in this article are included in the article's Creative Commons licence, unless indicated otherwise in a credit line to the material. If material is not included in the article's Creative Commons licence and your intended use is not permitted by statutory regulation or exceeds the permitted use, you will need to obtain permission directly from the copyright holder. To view a copy of this licence, visit http://creativecommons.org/licenses/by/4.0/.

\section{References}

1. Mieog JS, van der Hage JA, van de Velde CJ (2007) Neoadjuvant chemotherapy for operable breast cancer. Br J Surg 94(10):1189_ 1200. https://doi.org/10.1002/bjs.5894

2. Straver ME, van Adrichem JC, Rutgers EJ, Rodenhuis S, Linn SC, Loo CE, Gilhuijs KG, Oldenburg HS, Wesseling J, Russell NS, Antonini N, Vrancken Peeters MT (2008) Neoadjuvant systemic therapy in patients with operable primary breast cancer: more benefits than breast-conserving therapy. Ned Tijdschr Geneeskd 152(46):2519-2525

3. Gobardhan PD, de Wall LL, van der Laan L, ten Tije AJ, van der Meer DC, Tetteroo E, Poortmans PM, Luiten EJ (2013) The role of radioactive iodine-125 seed localization in breast-conserving therapy following neoadjuvant chemotherapy. Ann Oncol 24(3):668-673. https://doi.org/10.1093/annonc/mds475

4. Fisher B, Anderson S, Bryant J, Margolese RG, Deutsch M, Fisher ER, Jeong JH, Wolmark N (2002) Twenty-year follow-up of a randomized trial comparing total mastectomy, lumpectomy, and lumpectomy plus irradiation for the treatment of invasive breast cancer. N Engl J Med 347(16):1233-1241. https://doi. org/10.1056/NEJMoa022152

5. Veronesi U, Cascinelli N, Mariani L, Greco M, Saccozzi R, Luini A, Aguilar M, Marubini E (2002) Twenty-year follow-up of a randomized study comparing breast-conserving surgery with radical mastectomy for early breast cancer. N Engl J Med 347(16):12271232. https://doi.org/10.1056/NEJMoa020989

6. Jatoi I, Proschan MA (2005) Randomized trials of breast-conserving therapy versus mastectomy for primary breast cancer: a pooled analysis of updated results. Am J Clin Oncol 28(3):289-294. https ://doi.org/10.1097/01.coc.0000156922.58631.d7

7. Agarwal S, Pappas L, Neumayer L, Kokeny K, Agarwal J (2014) Effect of breast conservation therapy vs mastectomy on disease-specific survival for early-stage breast cancer. JAMA Surg 149(3):267-274. https://doi.org/10.1001/jamasurg.2013.3049

8. Hwang ES, Lichtensztajn DY, Gomez SL, Fowble B, Clarke CA (2013) Survival after lumpectomy and mastectomy for early stage invasive breast cancer: the effect of age and hormone receptor status. Cancer 119(7):1402-1411. https://doi.org/10.1002/cncr.27795

9. Lagendijk M, van Maaren MC, Saadatmand S, Strobbe LJA, Poortmans PMP, Koppert LB, Tilanus-Linthorst MMA, Siesling S (2018) Breast conserving therapy and mastectomy revisited: breast cancer-specific survival and the influence of prognostic factors in 129,692 patients. Int J Cancer 142(1):165-175. https://doi. org/10.1002/ijc.31034

10. van Maaren MC, de Munck L, de Bock GH, Jobsen JJ, van Dalen T, Linn SC, Poortmans P, Strobbe LJA, Siesling S (2016) 10 year survival after breast-conserving surgery plus radiotherapy compared with mastectomy in early breast cancer in the Netherlands: a population-based study. Lancet Oncol 17(8):1158-1170. https ://doi.org/10.1016/S1470-2045(16)30067-5

11. (EBCTCG) EBCTCG (2018) Long-term outcomes for neoadjuvant versus adjuvant chemotherapy in early breast cancer: meta-analysis of individual patient data from ten randomised trials. Lancet Oncol 19(1):27-39. https://doi.org/10.1016/S1470 -2045(17)30777-5

12. Rubio IT, Wyld L, Cardoso F, Curigliano G, Kovacs T, Poortmans P, Cortes J (2018) Perspectives on preoperative systemic treatment and breast conservative surgery: one step forward or two steps back? Breast 41:133-135. https://doi.org/10.1016/j.breas t.2018.07.008

13. CBO Kwaliteitsinstituut voor de Gezondheidszorg; Vereniging van Integrale Kankercentra Richtlijn 'Behandeling van het Mammacarcinoom'. [Guideline 'Treatment of Breast Cancer'.] Nationaal Borstkanker Overleg Nederland: Utrecht, 2012 
14. Vugts G, Maaskant-Braat AJ, Nieuwenhuijzen GA, Roumen RM, Luiten EJ, Voogd AC (2016) Patterns of care in the administration of neo-adjuvant chemotherapy for breast cancer. A populationbased study. Breast J 22(3):316-321. https://doi.org/10.1111/ tbj. 12568

15. Carey LA, Winer EP (2016) I-SPY 2-toward more rapid progress in breast cancer treatment. N Engl J Med 375(1):83-84. https:// doi.org/10.1056/NEJMe1603691

16. Rastogi P, Anderson SJ, Bear HD, Geyer CE, Kahlenberg MS, Robidoux A, Margolese RG, Hoehn JL, Vogel VG, Dakhil SR, Tamkus D, King KM, Pajon ER, Wright MJ, Robert J, Paik S, Mamounas EP, Wolmark N (2008) Preoperative chemotherapy: updates of National Surgical Adjuvant Breast and Bowel Project Protocols B-18 and B-27. J Clin Oncol 26(5):778-785. https://doi. org/10.1200/JCO.2007.15.0235

17. Mauri D, Pavlidis N, Ioannidis JP (2005) Neoadjuvant versus adjuvant systemic treatment in breast cancer: a meta-analysis. J Natl Cancer Inst 97(3):188-194. https://doi.org/10.1093/jnci/ dji021

18. Barranger E, Antomarchi J, Chamorey E, Cavrot C, Flipo B, Follana P, Peyrottes I, Chapellier C, Ferrero JM, Ihrai T (2015) Effect of neoadjuvant chemotherapy on the surgical treatment of patients with locally advanced breast cancer requiring initial mastectomy. Clin Breast Cancer 15(5):e231-235. https://doi. org/10.1016/j.clbc.2015.03.001

19. Mittendorf et al (2013) Impact of chemotherapy sequencing on local-regional failure risk in breast cancer patients undergoing breast conserving therapy

20. Arlow RL, Paddock LE, Niu X, Kirstein L, Haffty BG, Goyal S, Kearney T, Toppmeyer D, Stroup AM, Khan AJ (2018) Breastconservation therapy after neoadjuvant chemotherapy does not compromise 10-year breast cancer-specific mortality. Am J Clin Oncol 41(12):1246-1251. https://doi.org/10.1097/COC.00000 00000000456

21. Levy A, Borget I, Bahri M, Arnedos M, Rivin E, Vielh P, Balleyguier C, Rimareix F, Bourgier C (2014) Loco-regional control after neo-adjuvant chemotherapy and conservative treatment for locally advanced breast cancer patients. Breast J 20(4):381-387. https://doi.org/10.1111/tbj.12277

22. Cho JH, Park JM, Park HS, Park S, Kim SI, Park BW (2013) Oncologic safety of breast-conserving surgery compared to mastectomy in patients receiving neoadjuvant chemotherapy for locally advanced breast cancer. J Surg Oncol 108(8):531-536. https://doi.org/10.1002/jso.23439

23. Carrara GF, Scapulatempo-Neto C, Abrahão-Machado LF, Brentani MM, Nunes JS, Folgueira MA, Vieira RA (2017) Breastconserving surgery in locally advanced breast cancer submitted to neoadjuvant chemotherapy. Safety and effectiveness based on ipsilateral breast tumor recurrence and long-term follow-up. Clinics (Sao Paulo) 72(3):134-142. https://doi.org/10.6061/clini cs/2017(03)02

24. Shin HC, Han W, Moon HG, Im SA, Moon WK, Park IA, Park SJ, Noh DY (2013) Breast-conserving surgery after tumor downstaging by neoadjuvant chemotherapy is oncologically safe for stage III breast cancer patients. Ann Surg Oncol 20(8):25822589. https://doi.org/10.1245/s10434-013-2909-6

25. Mamounas EP, Anderson SJ, Dignam JJ, Bear HD, Julian TB, Geyer CE, Taghian A, Wickerham DL, Wolmark N (2012) Predictors of locoregional recurrence after neoadjuvant chemotherapy: results from combined analysis of National Surgical Adjuvant Breast and Bowel Project B-18 and B-27. J Clin Oncol 30(32):3960-3966. https://doi.org/10.1200/JCO.2011.40.8369

26. Caudle AS, Yu TK, Tucker SL, Bedrosian I, Litton JK, Gonzalez-Angulo AM, Hoffman K, Meric-Bernstam F, Hunt KK, Buchholz TA, Mittendorf EA (2012) Local-regional control according to surrogate markers of breast cancer subtypes and response to neoadjuvant chemotherapy in breast cancer patients undergoing breast conserving therapy. Breast Cancer Res 14(3):R83. https://doi.org/10.1186/bcr3198

27. Meyers MO, Klauber-Demore N, Ollila DW, Amos KD, Moore DT, Drobish AA, Burrows EM, Dees EC, Carey LA (2011) Impact of breast cancer molecular subtypes on locoregional recurrence in patients treated with neoadjuvant chemotherapy for locally advanced breast cancer. Ann Surg Oncol 18(10):2851-2857. https://doi.org/10.1245/s10434-011-1665-8

28. Jwa E, Shin KH, Kim JY, Park YH, Jung SY, Lee ES, Park IH, Lee KS, Ro J, Kim YJ, Kim TH (2016) Locoregional recurrence by tumor biology in breast cancer patients after preoperative chemotherapy and breast conservation treatment. Cancer Res Treat 48(4):1363-1372. https://doi.org/10.4143/crt.2015.456

29. Yang TJ, Morrow M, Modi S, Zhang Z, Krause K, Siu C, McCormick B, Powell SN, Ho AY (2015) The effect of molecular subtype and residual disease on locoregional recurrence in breast cancer patients treated with neoadjuvant chemotherapy and postmastectomy radiation. Ann Surg Oncol 22(Suppl 3):S495-501. https://doi.org/10.1245/s10434-015-4697-7

30. Swisher SK, Vila J, Tucker SL, Bedrosian I, Shaitelman SF, Litton JK, Smith BD, Caudle AS, Kuerer HM, Mittendorf EA (2016) Locoregional control according to breast cancer subtype and response to neoadjuvant chemotherapy in breast cancer patients undergoing breast-conserving therapy. Ann Surg Oncol 23(3):749-756. https://doi.org/10.1245/s10434-015-4921-5

31. Valachis A, Mamounas EP, Mittendorf EA, Hayashi N, Ishitobi M, Natoli C, Fitzal F, Rubio IT, Tiezzi DG, Shin HC, Anderson SJ, Hunt KK, Matsuda N, Ohsumi S, Totomi A, Nilsson C (2018) Risk factors for locoregional disease recurrence after breast-conserving therapy in patients with breast cancer treated with neoadjuvant chemotherapy: an international collaboration and individual patient meta-analysis. Cancer 124(14):29232930. https://doi.org/10.1002/cncr.31518

32. Bleicher RJ, Ruth K, Sigurdson ER, Daly JM, Boraas M, Anderson PR, Egleston BL (2016) Breast conservation versus mastectomy for patients with T3 primary tumors $(>5 \mathrm{~cm})$ : a review of 5685 medicare patients. Cancer 122(1):42-49. https://doi. org/10.1002/cncr.29726

33. Mazor AM, Mateo AM, Demora L, Sigurdson ER, Handorf E, Daly JM, Aggon AA, Anderson PR, Weiss SE, Bleicher RJ (2019) Breast conservation versus mastectomy in patients with T3 breast cancers $(>5 \mathrm{~cm})$ : an analysis of 37,268 patients from the National Cancer Database. Breast Cancer Res Treat 173(2):301-311. https://doi.org/10.1007/s10549-018-5007-4

34. Haque W, Verma V, Hatch S, Suzanne Klimberg V, Brian Butler E, Teh BS (2018) Response rates and pathologic complete response by breast cancer molecular subtype following neoadjuvant chemotherapy. Breast Cancer Res Treat 170(3):559-567. https://doi.org/10.1007/s10549-018-4801-3

35. Houssami N, Macaskill P, von Minckwitz G, Marinovich ML, Mamounas E (2012) Meta-analysis of the association of breast cancer subtype and pathologic complete response to neoadjuvant chemotherapy. Eur J Cancer 48(18):3342-3354. https://doi. org/10.1016/j.ejca.2012.05.023

36. Cortazar P, Zhang L, Untch M, Mehta K, Costantino JP, Wolmark N, Bonnefoi H, Cameron D, Gianni L, Valagussa P, Swain SM, Prowell T, Loibl S, Wickerham DL, Bogaerts J, Baselga J, Perou C, Blumenthal G, Blohmer J, Mamounas EP, Bergh J, Semiglazov V, Justice R, Eidtmann H, Paik S, Piccart M, Sridhara R, Fasching PA, Slaets L, Tang S, Gerber B, Geyer CE Jr, Pazdur R, Ditsch N, Rastogi P, Eiermann W, von Minckwitz G (2014) Pathological complete response and long-term clinical benefit in breast cancer: the CTNeoBC pooled analysis. Lancet 384(9938):164-172. https://doi.org/10.1016/S0140 $-6736(13) 62422-8$ 
37. von Minckwitz G, Untch M, Blohmer JU, Costa SD, Eidtmann H, Fasching PA, Gerber B, Eiermann W, Hilfrich J, Huober J, Jackisch C, Kaufmann M, Konecny GE, Denkert C, Nekljudova V, Mehta K, Loibl S (2012) Definition and impact of pathologic complete response on prognosis after neoadjuvant chemotherapy in various intrinsic breast cancer subtypes. J Clin Oncol 30(15):1796-1804. https://doi.org/10.1200/JCO.2011.38.8595

38. Mougalian SS, Hernandez M, Lei X, Lynch S, Kuerer HM, Symmans WF, Theriault RL, Fornage BD, Hsu L, Buchholz TA, Sahin AA, Hunt KK, Yang WT, Hortobagyi GN, Valero V (2016) Ten-year outcomes of patients with breast cancer with cytologically confirmed axillary lymph node metastases and pathologic complete response after primary systemic chemotherapy. JAMA Oncol 2(4):508-516. https://doi.org/10.1001/ jamaoncol.2015.4935
39. Kuerer HM, Rauch GM, Krishnamurthy S, Adrada BE, Caudle AS, DeSnyder SM, Black DM, Santiago L, Hobbs BP, Lucci A, Gilcrease M, Hwang RF, Candelaria RP, Chavez-MacGregor M, Smith BD, Arribas E, Moseley T, Teshome M, Miggins MV, Valero V, Hunt KK, Yang WT (2018) A clinical feasibility trial for identification of exceptional responders in whom breast cancer surgery can be eliminated following neoadjuvant systemic therapy. Ann Surg 267(5):946-951. https://doi.org/10.1097/SLA.00000 00000002313

Publisher's Note Springer Nature remains neutral with regard to jurisdictional claims in published maps and institutional affiliations. 